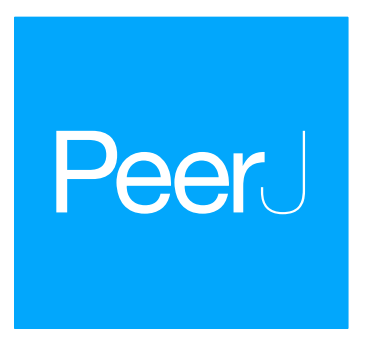

Submitted 6 November 2019

Accepted 2 September 2020

Published 2 October 2020

Corresponding authors

Liwen Zhang, lwzhang@yic.ac.cn

Guangxuan Han, 21046933@qq.com

Academic editor

Shalu Jhanwar

Additional Information and Declarations can be found on page 19

DOI 10.7717/peerj.10024

Copyright

2020 Zhang et al.

Distributed under

Creative Commons CC-BY 4.0

OPEN ACCESS

\section{Differentially expressed genes related to oxidoreductase activity and glutathione metabolism underlying the adaptation of Phragmites australis from the salt marsh in the Yellow River Delta, China}

\author{
Liwen Zhang ${ }^{1}$, Lin Chen ${ }^{1,2}$, Feng Lu ${ }^{3}$, Ziting Liu ${ }^{2}$, Siqun $\operatorname{Lan}^{1,4}$ and \\ Guangxuan $\operatorname{Han}^{1}$ \\ ${ }^{1}$ CAS Key Laboratory of Coastal Environmental Processes and Ecological Remediation, Yantai Institute of \\ Coastal Zone Research (YIC), Chinese Academy of Sciences (CAS); Shandong Key Laboratory of Coastal \\ Environmental Processes, YICCAS, Yantai, China \\ ${ }^{2}$ College of Environment and Planning, Liaocheng University, Liaocheng, China \\ ${ }^{3}$ Administration Committee of Shandong Yellow River Delta National Nature Reserve, Dongying, China \\ ${ }^{4}$ School of Resources and Environmental Engineering, Ludong University, Yantai, China
}

\section{ABSTRACT}

The common reed (Phragmites australis) is a dominant species in the coastal wetlands of the Chinese Yellow River Delta, where it tolerates a wide range of salinity. Recent environmental changes have led to the increase of soil salinity in this region, which has degraded much of the local vegetation. Clones of common reeds from the tidal marsh may have adapted to local high salinity habitat through selection on genes and metabolic pathways conferring salt tolerance. This study aims to reveal molecular mechanisms underlying salt tolerance in the tidal reed by comparing them to the salt-sensitive freshwater reed under salt stress. We employed comparative transcriptomics to reveal the differentially expressed genes (DEGs) between these two types of common reeds under different salinity conditions. The results showed that only three co-expressed genes were up-regulated and one co-expressed gene was down-regulated between the two reed types. On the other hand, 1,371 DEGs were exclusively up-regulated and 285 DEGs were exclusively down-regulated in the tidal reed compared to the control, while 115 DEGs were exclusively up-regulated and 118 DEGs were exclusively down-regulated in the freshwater reed compared to the control. From the pattern of enrichment of transcripts involved in salinity response, the tidal reed was more active and efficient in scavenging reactive oxygen species (ROS) than the freshwater reed, with the tidal reed showing significantly higher gene expression in oxidoreductase activity. Furthermore, when the reeds were exposed to salt stress, transcripts encoding glutathione metabolism were up-regulated in the tidal reed but not in the freshwater reed. DEGs related to encoding glutathione reductase (GR), glucose-6-phosphate 1dehydrogenase (G6PDH), 6-phosphogluconate dehydrogenase (6PD), glutathione Stransferase (GST) and L-ascorbate peroxidase (LAP) were revealed as especially highly differentially regulated and therefore represented candidate genes that could be cloned into plants to improve salt tolerance. Overall, more genes were up-regulated in the tidal reed than in the freshwater reed from the Yellow River Delta when under salt stress. The tidal reed efficiently resisted salt stress by up-regulating genes encoding 
for oxidoreductase activity and glutathione metabolism. We suggest that this type of common reed could be extremely useful in the ecological restoration of degraded, high salinity coastal wetlands in priority.

Subjects Ecology, Genetics, Marine Biology, Plant Science

Keywords Transcriptome analysis, Salt stress, Glutathione metabolism, Phragmites australis, Yellow River Delta, Oxidoreductase activity, Common reed, Coastal wetland, Transcription factors, Differential gene expression

\section{INTRODUCTION}

The common reed (Phragmites australis, family: Gramineae) is a perennial grass with high intraspecific plasticity and a large range in euploid number $(3 \times, 4 \times, 6 \times, 7 \times, 8 \times, 10 \times$, $11 \times$ and $12 \times$, with $x=12$ ) (Clevering \& Lissner, 1999), which reproduces both sexually and asexually. This cosmopolitan species is widely distributed in inland and coastal wetlands of temperate zones, and can grow in habitats with a wide range of salinity (Achenbach et al., 2013; Eller et al., 2017; Gao et al., 2012; Zhang, Wang \& Qi, 2017). Salt stress is one of the most crucial factors affecting the fitness of $P$. australis in coastal soils. Multiple studies have investigated how multiple plant traits, including morphological and physiological responses, are altered in P. australis when it experiences salt stress (Achenbach et al., 2013; Eller et al., 2017; Gorai et al., 2011; Guan et al., 2017; Mauchamp \& Mesleard, 2001; Yang, Xie \& Liu, 2014). With the development of new molecular techniques, it is now possible to describe the molecular changes of plants responding to salt stress. RNA-sequence (RNA-seq) is particularly well suited to study patterns of gene expression through the sequencing of organismal and tissue transcriptomes.

Such a comparative transcriptome analysis of salt-tolerant and salt-sensitive types of the same species can help to identify classes of genes related to salt tolerance, revealing the underlying molecular mechanisms of resistance to high salinity (Du et al., 2017; Guo et al., 2009; Jiang \& Deyholos, 2006; Mansuri et al., 2019; Peng et al., 2014). Recently, comparative transcriptomic studies on salt tolerance have been conducted in several plant species, such as Arabidopsis (Gong et al., 2005; Taji et al., 2004), wheat (Triticum aestivum) (Goyal et al., 2016), rice (Oryza sativa L.) (Do Amaral et al., 2016), and Fagopyrum tataricum (Wu et al., 2017). The genes and alleles identified in these studies could be employed in transgenic engineering or marker-assisted selection, improving the salt resistance of plants (Roy, Negrao \& Tester, 2014).

Many genes are involved in responding to salt stress in plants, and have been reported to be overexpressed as a component of salt resistance in crop plants. These genes include those involved in ion transport (e.g., the high affinity potassium transporter (HKT) gene family), tissue-specific tolerance (e.g., vacuolar $\mathrm{Na}^{+} / \mathrm{H}^{+}$antiporters (NHX)), compatible solutes (e.g., trehalose-6-phosphate synthase) and reactive oxygen species (ROS, e.g., glutathione S-transferase), and metabolism and signaling pathways (e.g., calcineurin-B like interacting protein kinases) (Roy, Negrao \& Tester, 2014). Mansuri et al. (2019) found that a salt-tolerant genotype of rice employed more efficient mechanisms of signal transduction of 
salt stress, influx and transport of $\mathrm{K}^{+}$, ionic and osmotic homeostasis, and ROS inhibition in response to salt stress compared to a salt-susceptible genotype. However, dominant salt-tolerant genes from specific species (and especially non-model species) still need to be identified to understand the salt-resistance of these species.

Transcription factors (TFs) also play an important role in resisting environmental stress for plants. Plants have evolved TFs to induce transcription of stress-responsive genes by binding to TF-binding sites of those genes. This regulation of gene expression in plants allows them to respond to environmental stress at a molecular and cellular level (Singh, Foley \& Onate-Sanchez, 2002). In particular, TFs are often involved in signaling responses to salinity. For example, TFs may identify the accumulation or elimination of ions through salt-inducible enzymes (transmembrane transporters), allowing the plant to stabilize ion balance and biosynthesize congenial solutes to adjust the vacuolar ionic balance (Guan et al., 2018). TFs also regulate cell membrane structures or synthesize a variety of pathogenesis-related proteins and hormones, both of which can be relevant to tolerating higher salinity (Guan et al., 2018). More than 30 TFs families in plants have been identified as playing important roles in responding to salt stress, including basic Helix-Loop-Helix (bHLH), WRKY, the heat shock factors (HSF), dehydration responsive element binding protein (DREB), MYB, N-acetyl-L-cysteine (NAC), bZIP and WRKY families (Du et al., 2017; Hickman et al., 2013; Roy, Negrao \& Tester, 2014).

The Yellow River Delta, located at the intersection of the Yellow River and the Bohai Gulf, is important for both social development and biodiversity conservation in the region. Phragmites australis is one of the dominant species and main primary producers in these coastal wetlands, including tidal marsh of the Yellow River Delta. Beyond primary production, common reeds provide important ecosystem functions for this region, such as creating habitat for insects, benthic organisms, water birds and other animals, as well as protecting the structure of the shoreline and purifying bodies of water in the Delta. However, the coastal wetlands in the Yellow River Delta have degraded in recent years due to climate change such as increasing temperature and human disruptions such as drainage (Cong et al., 2019). Consequently, the soil salinity has increased in these degraded wetlands (Guan et al., 2013). Given the observed salt tolerance of the common reed, this plant could serve an important role in the ecological restoration of wetlands in this region.

In the Yellow River Delta, salinity is considered as a significant factor influencing the genetic diversity and ecological divergence of common reeds (Guo et al., 2003; Gao et al., 2012), and two main types of common reeds have been identified: common reeds from tidal marshes (i.e., the tidal reed) and common reeds from riverside marshes (i.e., the freshwater reed) (Zhang et al., 2018). The genetic variation of common reeds between tidal and freshwater reeds is more than that among individuals within group, providing the evidence for adaptive differentiation to salinity in the Yellow River Delta (Zhang et al., 2018). Furthermore, the manipulated experiment has revealed that the tidal reed has a higher salinity tolerance in eco-physiological responses than the freshwater reed from the Yellow River Delta (Chen et al., 2020). This salt tolerance is specifically seen in the greater $\mathrm{Na}^{+}$efflux in roots of the tidal reed, greater proline content, and greater antioxidant enzyme activity in leaves of the tidal reed (Chen et al., 2020). However, few studies have 
been conducted to compare differential gene expression between the salinity-tolerant and the salinity-sensitive types of $P$. australis under salt stress. In this study, we set out to describe the molecular mechanism underlying greater salt tolerance in the tidal reed compared to the freshwater reed in the Yellow River Delta. To achieve this, we use transcriptomics to identify differentially expressed genes of the two types of common reeds from distinct habitats, providing us with a number of candidate genes to help explain the basis of salt tolerance in the common reed.

\section{METHODS}

\section{Plant sampling}

Samples of the common reed used in the experiment were taken in the Yellow River Delta, Shandong Province, in northeast China. No permit is required to collect common reeds in this region, because it is a dominant species. Dr. Bo Guan and Dr. Liwen Zhang identified the plant materials. The climate of this region is warm-temperate, with an average annual temperature of $12.2^{\circ} \mathrm{C}$. The average annual precipitation is $609.5 \mathrm{~mm}$, and precipitation mainly falls in the summer. We collected the rhizomes of $P$. australis from the tidal marsh $\left(37^{\circ} 43^{\prime} 32^{\prime \prime} \mathrm{N}, 119^{\circ} 13^{\prime} 55^{\prime \prime} \mathrm{E}\right)$ and the freshwater marsh $\left(37^{\circ} 45^{\prime} 58^{\prime \prime} \mathrm{N}, 119^{\circ} 10^{\prime} 6^{\prime \prime} \mathrm{E}\right)$ in May 2018. The tidal marsh was inundated by the sea tide irregularly, and the salinity of this habitat was measured to be $5.87 \pm 0.20 \mathrm{mS} / \mathrm{cm}$ (Zhang et al., 2018). The freshwater riverside marsh was located in the riverside of the Yellow River, and the salinity of this habitat was measured to be $1.60 \pm 0.18 \mathrm{mS} / \mathrm{cm}$ (Zhang et al., 2018).

We cultivated seedlings in an artificial climate chamber at the Yantai Institute of Coastal Zone Research, Chinese Academy of Sciences. Plants were kept at $28 \pm 2{ }^{\circ} \mathrm{C}$ in the daytime and $20 \pm 2{ }^{\circ} \mathrm{C}$ during the night, with a photoperiod of $14 \mathrm{~h}$ for the light period and 10 $\mathrm{h}$ for the dark period. First, the rhizomes were submerged in freshwater on May 16, 2018 until they generated fibrous roots and shoots from the nodes. Then we transplanted one seedling into one pot (caliber: $11.0 \mathrm{~cm}$; bottom diameter: $8.0 \mathrm{~cm}$; height: $10.0 \mathrm{~cm}$ ) filled with sand and watered each plant with $150 \mathrm{~mL}$ of Hoagland nutrient solution every other day.

The experiment was conducted on July 31, 2018. We chose 12 common reed individuals (height of tidal reeds were $77.7 \pm 4.67 \mathrm{~cm}, n=6$; height of freshwater reeds were $73.8 \pm 2.65$ $\mathrm{cm}, n=6$; mean $\pm \mathrm{se}$ ), and applied the control to three individuals of each type, and the salt stress treatment to three individuals of each type. The control had $0 \mathrm{mmol} / \mathrm{L} \mathrm{NaCl}$ in the nutrient solution (hereafter referred to as "T0" for tidal reeds and "F0" for freshwater reeds) while the salt stress treatment had $300 \mathrm{mmol} / \mathrm{L} \mathrm{NaCl}$ in the nutrient solution (hereafter referred to as "T300" and "F300"). To avoid osmotic shock, salinity was gradually increased at a rate of $50 \mathrm{mmol} / \mathrm{L} \mathrm{NaCl}$ per day to the treatment salinity $(300 \mathrm{mmol} / \mathrm{L} \mathrm{NaCl})$, over the course of six days. We then sampled the leaves $12 \mathrm{~h}$ after the salt treatment reached 300 $\mathrm{mmol} / \mathrm{L} \mathrm{NaCl}$. Six mature leaves were taken from each individual and pooled as a single sample. The leaf samples were then frozen in liquid nitrogen. 


\section{RNA extraction, library construction and sequence analysis}

Total RNA was extracted using the RNAprep PurePlant Kit (No.DP441; Polysaccharides \& Polyphenolics-rich; Tiangen Co. Ltd, Beijing, China). RNA was isolated by using an on-column DNase I digestion set. The cDNA libraries were prepared from RNA samples according to the Illumina protocol for paired-end sequencing. Sequencing was performed on the Illumina HiSeq X Ten platform (Illumina San Diego CA, USA) at Novogene Bioinformatics Technology Co., Ltd (Beijing, China). RNAseq was performed in triplicate.

\section{Transcriptome assembly and data analysis}

We processed raw reads in fastq format using in-house perl scripts. Cleaned reads were obtained by removing reads containing adapters, reads containing ploy- $\mathrm{N}$ and low quality reads from the raw data. We calculated Q20, Q30, GC-content and sequence duplication level of the cleaned data. Cleaned data with high quality were used in all downstream analyses. The left files (read 1 files) from all libraries for the same sample were pooled into a single left.fq file, and the right files (read 2 files) into a single right.fq file. Transcriptome assembly was accomplished based on left.fq and right.fq using Trinity with min_kmer_cov set to 2 by default and all other parameters set as defaults (Grabherr et al., 2011). The longest assembled transcript of a gene was taken as a unigene.

Gene function was annotated based on the following databases: NCBI non-redundant protein sequences $(\mathrm{Nr}), \mathrm{NCBI}$ non-redundant nucleotide sequences $(\mathrm{Nt})$, protein family (Pfam), clusters of orthologous groups of proteins (KOG / COG), a manually annotated and reviewed protein sequence database (Swiss-Prot), Kyoto encyclopedia of genes and genomes (KEGG) ortholog database (KO) and gene ontology (GO).

Prior to differential gene expression analysis, the read counts were adjusted for each sequenced library through one scaling normalized factor using the edgeR package. Differential expression analysis of two samples was performed using the DEGseq2 (2014) $\mathrm{R}$ package (Love, Huber \& Anders, 2014). DESeq2 estimated the dispersion according to the replicates, and this guaranteed the unreplicated condition did not have larger variation than the replicated one. The $p$-value was adjusted to $q$-value (Storey \& Tibshirani, 2003). $\mid \log _{2}$ (foldchange) $\mid>1$ and $q$-value $<0.05$ (i.e., False discovery rate; FDR) were set as the threshold for significantly differential expression.

GO enrichment analysis of the differentially expressed genes (DEGs) was implemented by the GOseq2 R package using a Wallenius non-central hyper-geometric distribution (Young et al., 2010), which can adjust for gene length bias in DEGs. Differential gene cluster analysis (H-cluster) was used to determine the clustering pattern of differential gene expression under different experimental conditions $(0$ and $300 \mathrm{mmol} / \mathrm{L} \mathrm{NaCl}$ ). A differential gene set was obtained for each comparison combination, and the FPKM (fragments per kilobase of exon per million reads mapped) values of all comparison combinations were aggregated in each experimental group or sample, which were used to draw the heat map. KOBAS (Mao et al., 2005) software was employed to test the statistical enrichment of differential expression genes in KEGG pathways (Kanehisa et al., 2008) (http://www.genome.jp/kegg/). The identification of differentially expressed TFs was conducted in the iTAK software (Zheng et al., 2016). 
Table 1 Summary of the sequencing data from different samples. Error rate: the percentage of the error bases; Q20: percentage of the bases with $Q_{\text {phred }}>20$ (error rate $<1 \%$ ); Q30: the percentage of the bases with $Q_{\text {phred }}>30$ (error rate $<0.1 \%$ ).

\begin{tabular}{|c|c|c|c|c|c|c|c|c|}
\hline $\begin{array}{l}\text { Plant } \\
\text { source }\end{array}$ & $\begin{array}{l}\text { Treatments } \\
(\mathrm{mmol} / \mathrm{L} \mathrm{NaCl})\end{array}$ & Replicate & $\begin{array}{l}\text { Cleaned } \\
\text { reads }\end{array}$ & $\begin{array}{l}\text { Cleaned } \\
\text { bases }(\mathrm{Gb})\end{array}$ & $\begin{array}{l}\text { Error } \\
\text { rate }(\%)\end{array}$ & Q20(\%) & Q30(\%) & $\mathrm{GC}(\%)$ \\
\hline \multirow[t]{6}{*}{ Tidal reed } & 0 & 1 & 47479034 & 7.12 & 0.03 & 97.35 & 93.04 & 56.07 \\
\hline & & 2 & 56205668 & 8.43 & 0.03 & 96.52 & 91.30 & 53.22 \\
\hline & & 3 & 61753102 & 9.26 & 0.03 & 96.68 & 91.62 & 55.65 \\
\hline & 300 & 1 & 44151272 & 6.62 & 0.03 & 97.45 & 93.23 & 56.16 \\
\hline & & 2 & 52103092 & 7.82 & 0.03 & 97.41 & 93.16 & 54.16 \\
\hline & & 3 & 48605796 & 7.29 & 0.03 & 97.38 & 93.07 & 55.08 \\
\hline \multirow[t]{6}{*}{ Freshwater reed } & 0 & 1 & 48801590 & 7.32 & 0.03 & 97.39 & 93.09 & 54.54 \\
\hline & & 2 & 55177990 & 8.28 & 0.03 & 96.70 & 91.66 & 54.01 \\
\hline & & 3 & 51626222 & 7.74 & 0.03 & 96.61 & 91.54 & 54.13 \\
\hline & 300 & 1 & 51678770 & 7.75 & 0.03 & 96.73 & 91.72 & 55.11 \\
\hline & & 2 & 49186016 & 7.38 & 0.03 & 96.69 & 91.65 & 54.63 \\
\hline & & 3 & 49211928 & 7.38 & 0.03 & 96.64 & 91.56 & 55.16 \\
\hline
\end{tabular}

\section{RESULTS}

\section{Sequence quality and assembly}

In total, $92.39 \mathrm{~Gb}$ of high quality sequences were obtained from common reed leaves of all the treatments (Table 1). The cleaned bases of the tidal reed samples ranged from 6.62 to $9.26 \mathrm{~Gb}$, and that of the freshwater reed samples ranged from 7.32 to $8.28 \mathrm{~Gb}$. The average error rates of the sequences were $0.03 \%$ (Table 1). The percentage of the bases with Qphred $>20$ or Qphred $>30$ was over $90 \%$. The sequencing data were assembled into 298,412 transcripts, and their length ranged from 201 to 31,111 bases (mean length $=1,127$ bases and median length $=779$ bases). In total, 260,311 unigenes were obtained (mean length was 1,252 bases and median length was 941 bases), and the total length of the unigenes was $325.9 \mathrm{Mb}(325,875,256$ bases $)$.

\section{Differential gene expression in two common reed types responding to salt stress}

Differential gene expression patterns between the samples and treatments is shown in a heat-map (Fig. 1) and Venn diagram (Figs. 2 and 3; Dataset S1). The Venn diagram shows 1,374 up-regulated genes and 286 down-regulated genes in T300 (i.e., the tidal reed under $300 \mathrm{mmol} / \mathrm{L} \mathrm{NaCl}$ treatment) compared to T0 (i.e., the tidal reed under 0 $\mathrm{mmol} / \mathrm{L} \mathrm{NaCl}$ treatment). In the freshwater reed, there were 118 up-regulated genes and 119 down-regulated genes in F300 (i.e., the freshwater reed under $300 \mathrm{mmol} / \mathrm{L} \mathrm{NaCl}$ treatment) compared to F0 (i.e., the freshwater reed under $0 \mathrm{mmol} / \mathrm{L} \mathrm{NaCl}$ treatment) (Figs. 2 and 3; Dataset S1). Only three genes were up-regulated in both "T300 vs T0" and "F300 vs F0", and only one gene was mutually down-regulated in both "T300 vs T0" and "F300 vs F0". However, 11,514 up-regulated genes and 4,276 down-regulated genes were detected for "T0 vs F0"; 7,284 up-regulated genes and 2,407 down-regulated genes were detected for "T300 vs F300". 


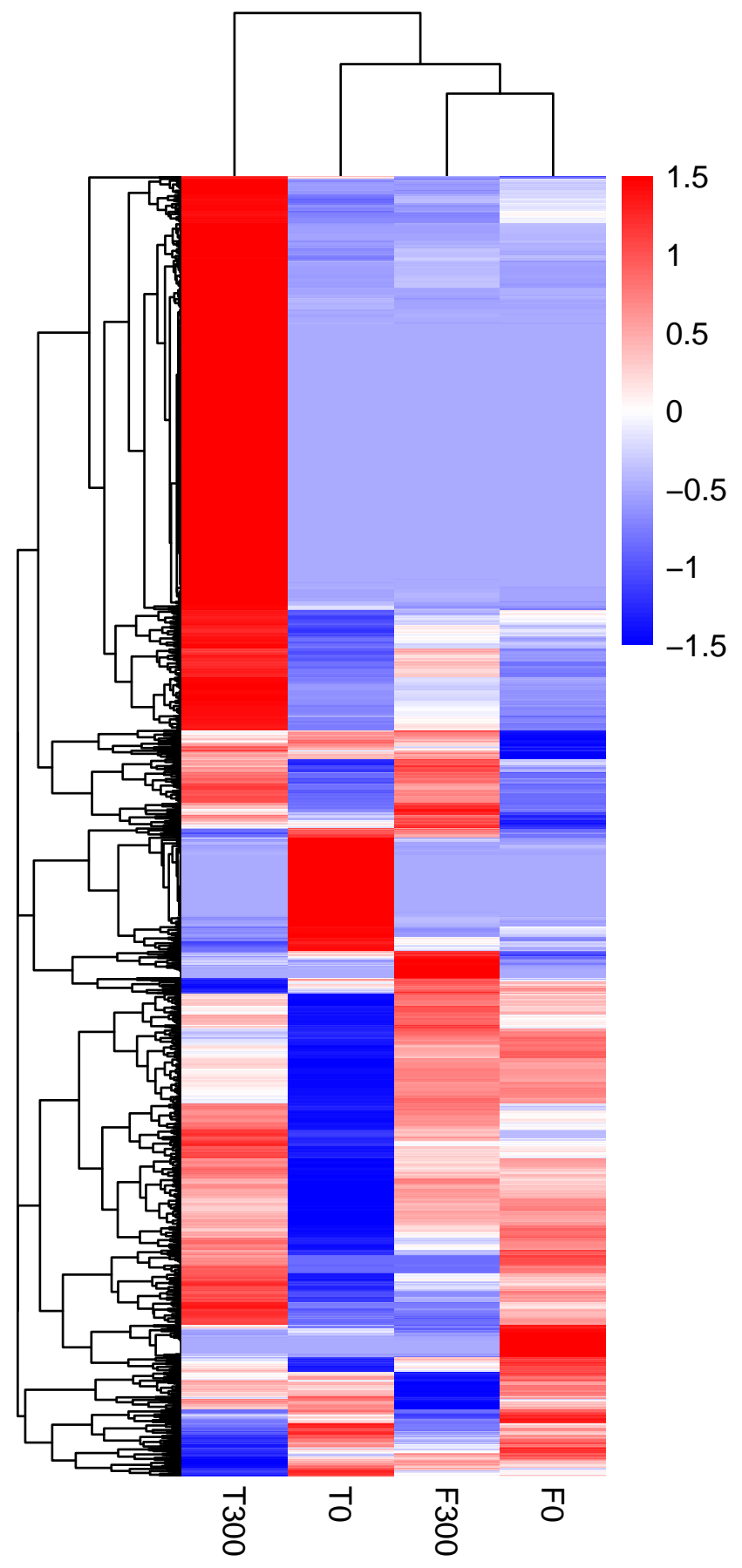

Figure 1 Heat-map of Phragmites australis expression level data. T0 is the tidal reed with $0 \mathrm{mmol} / \mathrm{L}$ $\mathrm{NaCl}$ treatment, and T300 is the tidal reed with $300 \mathrm{mmol} / \mathrm{L} \mathrm{NaCl}$ treatment. F0 indicates the freshwater reed with $0 \mathrm{mmol} / \mathrm{L} \mathrm{NaCl}$ treatment, and $\mathrm{F} 300$ is the freshwater reed with $300 \mathrm{mmol} / \mathrm{L} \mathrm{NaCl}$ treatment. Red colors indicate high expression, while blue colors indicate low expression. The color ranges from red to blue, indicating that $\log _{10}(\mathrm{FPKM}+1)$ ranges from large to small.

Full-size DOI: $10.7717 /$ peerj.10024/fig-1 


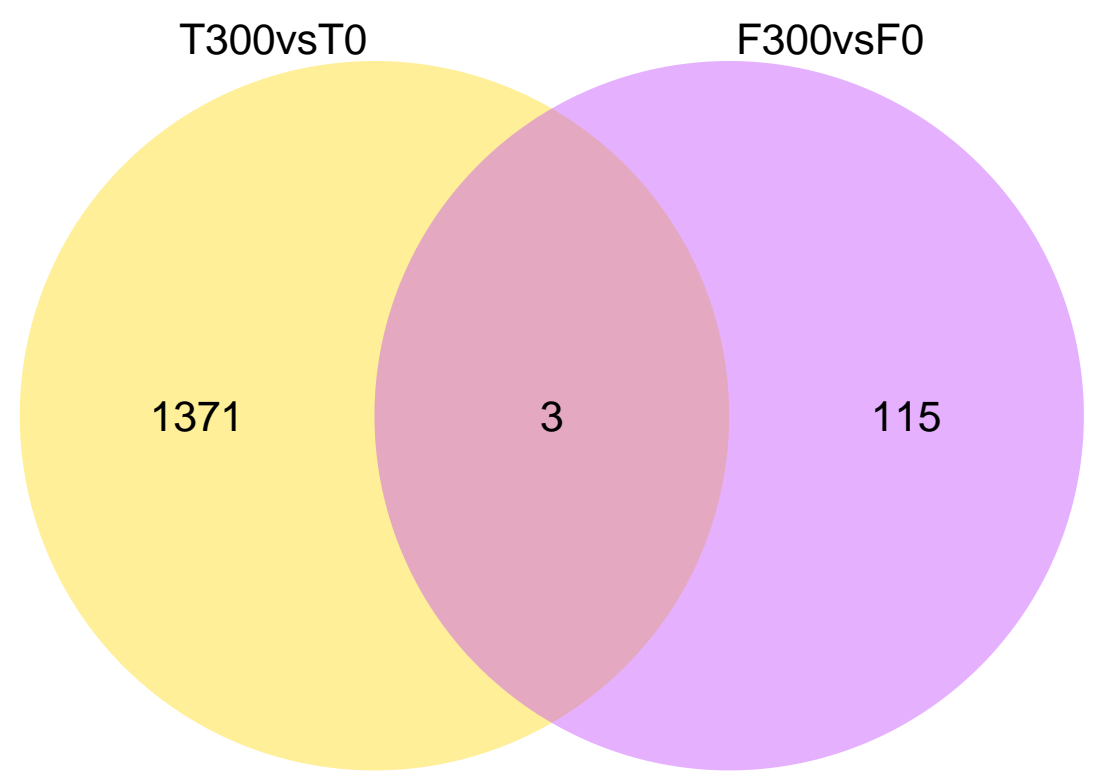

Figure 2 Venn diagrams showing the number of up-regulated genes of "T300 vs T0" and "F300 vs F0". T0 is the tidal reed with $0 \mathrm{mmol} / \mathrm{L} \mathrm{NaCl}$ treatment, and T300 is the tidal reed with $300 \mathrm{mmol} / \mathrm{L} \mathrm{NaCl}$ treatment. F0 indicates the freshwater reed with $0 \mathrm{mmol} / \mathrm{L} \mathrm{NaCl}$ treatment, and $\mathrm{F} 300$ is the freshwater reed with $300 \mathrm{mmol} / \mathrm{L} \mathrm{NaCl}$ treatment.

Full-size DOI: 10.7717/peerj.10024/fig-2

From the GO enrichment analysis of DEGs in the leaves of tidal reeds under salt stress compared to the control ("T300 vs T0"), the significantly up-regulated enriched GO terms for molecular functions were oxidoreductase activity (GO:0016491; DEGs = 136; $q$-value $=0.04), \mathrm{NAD}(\mathrm{P})^{+}$transhydrogenase activity $(\mathrm{GO}: 0008746 ; \mathrm{DEGs}=4 ; q$-value $=$ $0.04), \mathrm{NAD}(\mathrm{P})^{+}$transhydrogenase activity (AB-specific) activity (GO:0008750; $\mathrm{DEGs}=4$; q-value $=0.04)$, and oxidoreductase activity, acting on $\mathrm{NAD}(\mathrm{P}) \mathrm{H}$ with $\mathrm{NAD}(\mathrm{P})$ as acceptor (GO:0016652; DEGs = 4; q-value = 0.04) (Fig. 4; Datasets S2-S3). For biological processes, the significantly up-regulated enriched GO terms were methanogenesis from acetate (GO:0019385; DEGs $=4 ; q$-value $=0.02$ ), and oxidation-reduction process (GO:0055114; DEGs $=129 ; q$-value $=0.02$ ) (Fig. 4). On the other hand, there were no significantly down-regulated enriched GO terms for "T300 vs T0" (Fig. S1), and up-regulated or down-regulated enriched GO terms for "F300 vs F0" (Figs. S2-S3).

Furthermore, for "T300 vs T0", the up-regulated pathways that were significantly enriched were glutathione metabolism (KEGG ID: ko00480), and cutin, suberine and wax biosynthesis (KEGG ID: ko00073) (Fig. 5; Dataset S4), however, there were no significantly enriched down-regulated pathways for "T300 vs T0" (Fig. S4). In the case of the glutathione metabolism pathway (Kanehisa \& Sato, 2019), there were three up-regulated genes related to glutathione reductase (GR; EC 1.8.1.7, K00383) (Cluster-26447.33049, Cluster-26447.95407, and Cluster-26447.95406 with $\log _{2}$ fold changes of 9.08, 9.97 and 6.91, respectively; Table 2). These three up-regulated genes returned Blast hits to the protein "GSHRP_TOBAC", "GSHRC_ORYSJ" and "GSHRC_ORYSJ" (Table 2). Two upregulated genes (Cluster-26447.109452 (9.75, “G6PD_SOLTU”) and (Cluster-26447.60729 


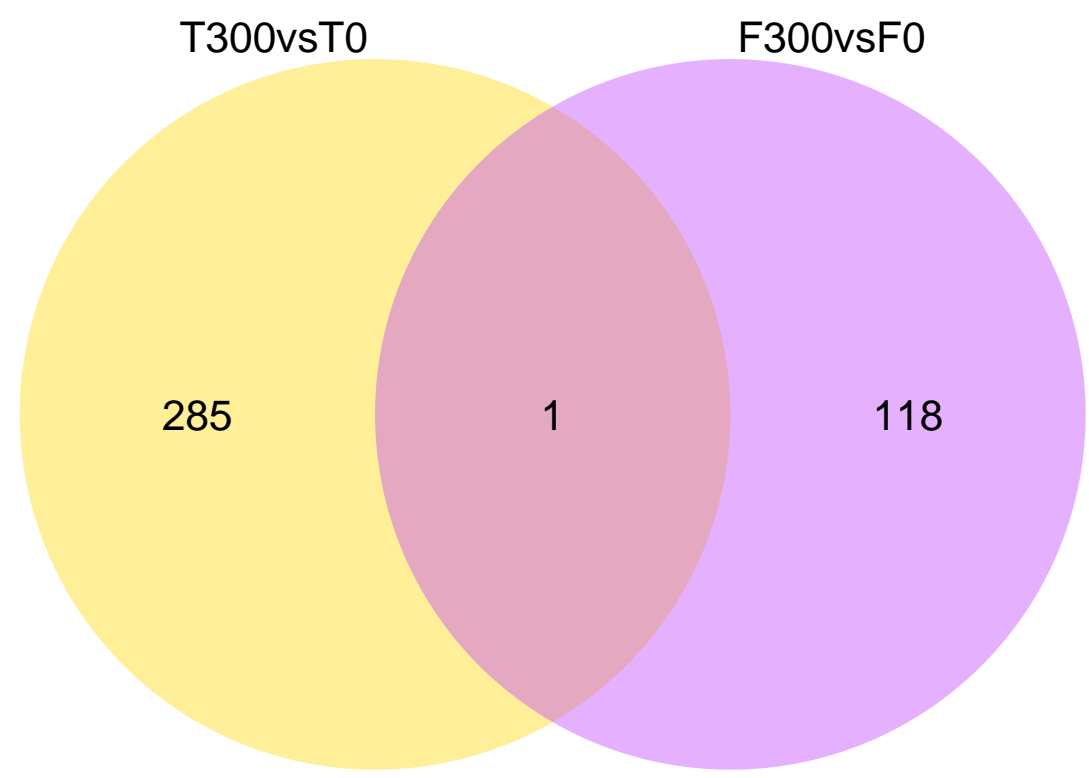

Figure 3 Venn diagrams showing the number of down-regulate genes of "T300 vs T0" and "F300 vs F0". T0 is the tidal reed with $0 \mathrm{mmol} / \mathrm{L} \mathrm{NaCl}$ treatment, and T300 is the tidal reed with $300 \mathrm{mmol} / \mathrm{L} \mathrm{NaCl}$ treatment. $\mathrm{F} 0$ indicates the freshwater reed with $0 \mathrm{mmol} / \mathrm{L} \mathrm{NaCl}$ treatment, and $\mathrm{F} 300$ is the freshwater reed with $300 \mathrm{mmol} / \mathrm{L} \mathrm{NaCl}$ treatment.

Full-size DOI: 10.7717/peerj.10024/fig-3

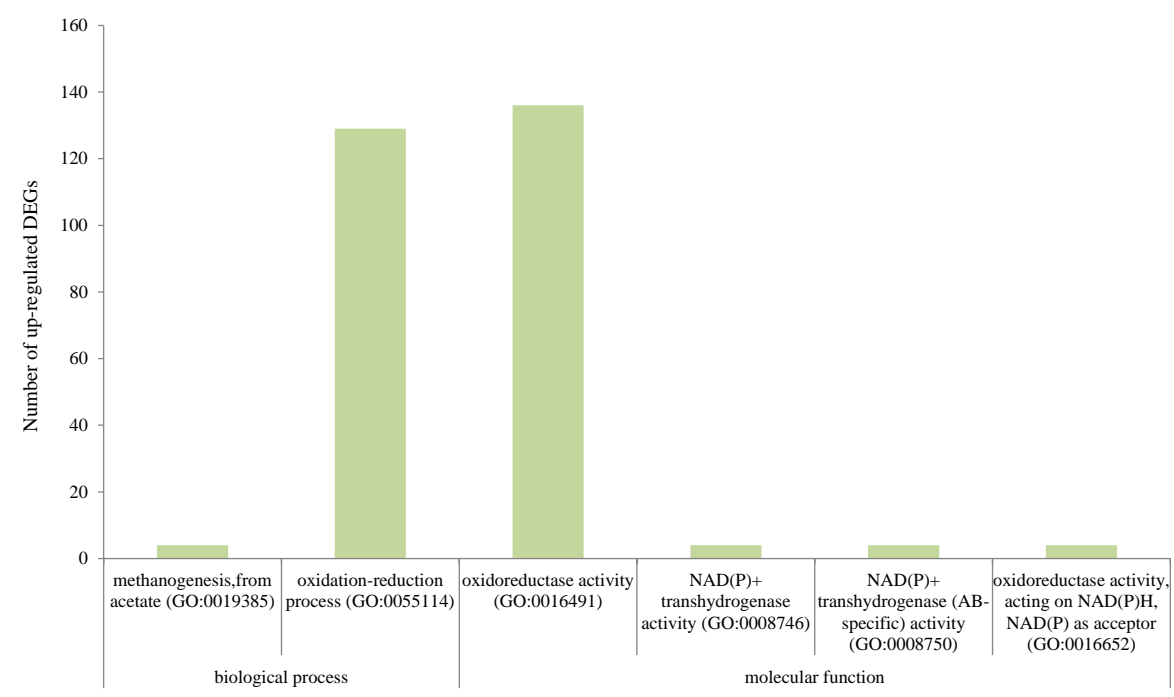

Figure 4 The statistically significant up-regulated GO categories of differentially expressed genes in the leaves of tidal reeds for "T300 vs T0". T0 is the tidal reed with $0 \mathrm{mmol} / \mathrm{L} \mathrm{NaCl}$ treatment, and T300 is the tidal reed with $300 \mathrm{mmol} / \mathrm{L} \mathrm{NaCl}$ treatment.

Full-size DOI: 10.7717/peerj.10024/fig-4

(9.36, “G6PD4_ARATH”); Table 2) were related to glucose-6-phosphate 1-dehydrogenase (G6PDH; EC 1.1.1.49; K00036). One up-regulated gene (Cluster-26447.153858 (8.78, “6PGD1_ORYSJ”)) and one down-regulated gene (Cluster-26447.153852 (-9.35, 


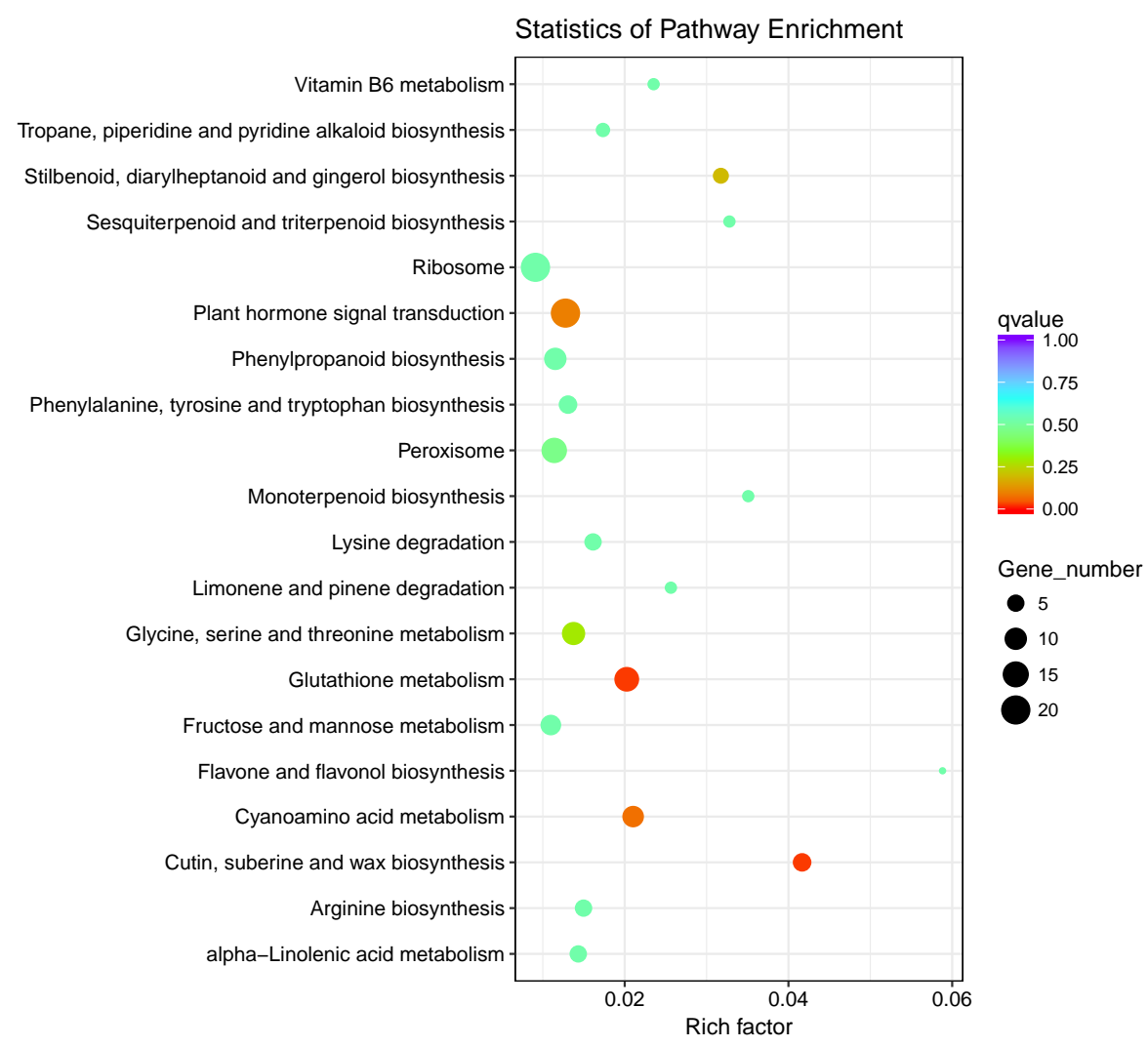

Figure 5 The up-regulated pathways of differentially expressed genes in the leaves of tidal reeds for "T300 vs T0". T0 is the tidal reed with $0 \mathrm{mmol} / \mathrm{L} \mathrm{NaCl}$ treatment, and T300 is the tidal reed with 300 $\mathrm{mmol} / \mathrm{L} \mathrm{NaCl}$ treatment.

Full-size DOI: 10.7717/peerj.10024/fig-5

“6PGD1_ORYSJ”); Table 2) were related to 6-phosphogluconate dehydrogenase (6PGD; EC 1.1.1.44, K00033). Six up-regulated genes contributed to the GST (EC 2.5.1.18, K00799; Table 2): Cluster-26447.125406 (8.16, “GSTU6_ORYSJ”), Cluster-26447.160591 (5.45, “GSTF1_ORYSJ”), Cluster-26447.177110 (5.07, “GSTF4_MAIZE”), Cluster26447.206365 (9.68, “GSTU6_ORYSJ”), Cluster-26447.141508 (7.12, “GSTU6_ORYSJ”), and Cluster-26447.177111 (10.31, “GSTF4_MAIZE”). Only one up-regulated gene (Cluster-26447.116962 (3.71, “APX2_ORYSJ”); Table 2) was related to L-ascorbate peroxidase (LAP; EC 1.1.1.1.11, K00434). On the other hand, there were no significantly up-regulated or down-regulated enriched pathways for "F300 vs F0" (Figs. S5-S6).

The top two most enriched GO terms (based on DEGs numbers and $q$-value) in "T0 vs F0" were metabolic process (GO:0008152; DEGs $=5568 ; q$-value $<0.001)$ and organic cyclic compound biosynthesis (GO:1901362; DEGs = 1478; $q$-value<0.001) (Fig. S7), while the top two most enriched GO terms of "T300 vs F300" were oxidation-reduction process (GO:0055114; DEGs $=669 ; q$-value $<0.01$ ) and oxidoreductase activity (GO:0016491; DEGs=689; q-value $<0.001$ ) (Fig. S8). The top two pathway enrichments (based on DEGs numbers and $q$-value) of "T0 vs F0" were plant hormone signal transduction (KEGG: ko04075; DEGs = 164; $p$-value<0.001) and plant-pathogen interaction (KEGG: ko04626; 
DEGs $=132 ; q$-value $<0.01$ ) (Fig. S9). For "T300 vs F300", they were protein processing in endoplasmic reticulum (KEGG: ko04141; DEGs $=112$; $q$-value $<0.01$ ) and plant-pathogen interaction (KEGG: ko04626; DEGs $=89$; $q$-value $<0.01$ ). Notably, glutathione metabolism (KEGG: ko00480; DEGs = 46; $q$-value $<0.01$ ) was also enriched (Fig. S10).

\section{Expression profiles of TF genes}

For "T300 vs T0", the differentially expressed TFs with more than three genes were: WRKY (Five genes: One WRKY42, two WRKY70 and two WRKY31), Orphans (Five genes: two APRR5, one ETR2, one DAR1 and one SALR), NAC (Four genes: one NAC48, one NAM-B1, one NAC021 and one NAM-B1), AP2-EREBP (Four genes: one PTI5, one RAP2-2, one DREB2A and one ERF008) and G2-like (Four genes: two PHL1 and two LUX) which were up-regulated; Orphans (Four genes: one EMB1674, one ARR6, one ARR8 and one TIFY10B), FAR1 (Three genes: two FRS6 and one FRS5) and MYB (Three genes: one MADS33, one DIVARICATA and one MYB1R1) which were down-regulated (Fig. 6 and Table 3; Dataset S5). For "F300 vs F0", the differentially expressed TFs with more than three genes were the up-regulated TFs of genes in the NAC family (Four genes: one NAC056, one NAM-B2, one NAC010, and one NAM-B2) (Fig. 7 and Table 3; Dataset S5). Many more TFs were differentially expressed in comparing "T0 vs F0" and "T300 vs F300" than in "T300 vs T0" and "F300 vs F0" (Table S1; Dataset S5). For example, for "T0 vs F0" there were 96 up-regulated WRKY genes, 42 up-regulated NAC genes, and 72 up-regulated AP2-EREBP genes. For "T300 vs F300", there were 87 up-regulated WRKY genes, 42 up-regulated NAC genes, and 27 up-regulated AP2-EREBP genes.

\section{DISCUSSION}

\section{Differential gene expression}

In this study, we compared the transcriptomes of salt-tolerant and salt-sensitive common reeds when treated with salt stress versus a control. We found that under salt stress, the salt-tolerant reed had more up-regulated genes (1374) and down-regulated genes (286) than the salt-sensitive reed (up-regulated genes: 118; down-regulated genes: 119).

Previously, Holmes et al. (2016) compared transcriptomes of P. australis from low salinity and high salinity sites of the Gippsland Lakes area of southeastern Australia. In their study, the number of up-regulated genes in reeds under salt stress from the highly saline sites (54 DEGs) was similar with that of reeds from low salinity sites (53 DEGs). However, the number of down-regulated genes from low salinity sites (60 DEGs) was much greater than that from highly saline sites (9 DEGs). The discrepancy of number of genes of the salt-tolerant reed and the salt-sensitive reed in our study was much larger than that found by Holmes et al. (2016). Thus, more salt-tolerant genes may be detected in our study. Time scale may be one of the reasons leading to the discrepancy between the studies. Gene expression is sensitive to time scale, with long-term and short-term response to salt stress being different. For example, the first phase of a leaf's physiological response to $\mathrm{NaCl}$-stress is in $0-4 \mathrm{~h}$, which is an initial dehydration phase. This is followed by $\mathrm{NaCl}$ accumulation (4-24 h), and by a restoration of osmotic homeostasis at a new ionic level by $24 \mathrm{~h}$. Finally, from 24 to $72 \mathrm{~h}$ beyond, there is an adjustment to a steady ion balance or 
Table 2 Differently expressed genes related to glutathione reductase in "T300 vs T0". T0 means the tidal reed with $0 \mathrm{mmol} / \mathrm{L} \mathrm{NaCl}$ treatment. T300 is the tidal reed with $300 \mathrm{mmol} / \mathrm{L} \mathrm{NaCl}$ treatment. UniProt annotation is from Blastx Swiss-Prot. Gene product and organism come from Blastx NT GenBank. The gene sequences can be can be found in https://doi.org/10.6084/m9.figshare.12629885.v4.

\begin{tabular}{|c|c|c|c|c|c|}
\hline Contig sequence ID & $\begin{array}{l}\text { UniProt } \\
\text { annotation }\end{array}$ & $\begin{array}{l}\text { FDR } \\
(q \text {-value })\end{array}$ & $\begin{array}{l}\log _{2} \text {-fold } \\
\text { expression } \\
\text { change }\end{array}$ & Gene product and organism & Go terms \\
\hline Cluster-26447.33049 & GSHRP_TOBAC & 0.037 & 9.08 & $\begin{array}{l}\text { Predicted: Setaria } \\
\text { italica glutathione } \\
\text { reductase, chloroplastic } \\
\text { (LOC101762040), transcript } \\
\text { variant X1, mRNA. }\end{array}$ & $\begin{array}{l}\text { Biological process: small } \\
\text { molecule metabolic process, } \\
\text { cellular homeostasis, cel- } \\
\text { lular aromatic compound } \\
\text { metabolic process, organic } \\
\text { cyclic compound metabolic } \\
\text { process, cellular aromatic } \\
\text { compound metabolic pro- } \\
\text { cess. Cellular component: } \\
\text { intracellular part. }\end{array}$ \\
\hline Cluster-26447.95407 & GSHRC_ORYSJ & 0.012 & 9.97 & $\begin{array}{l}\text { Predicted: Setaria italica glu- } \\
\text { tathione reductase, cytosolic } \\
\text { (LOC101759106), mRNA. }\end{array}$ & $\begin{array}{l}\text { Molecular function: coen- } \\
\text { zyme binding, anion bind- } \\
\text { ing. }\end{array}$ \\
\hline Cluster-26447.95406 & GSHRC_ORYSJ & 0.004 & 6.94 & $\begin{array}{l}\text { Phyllostachys edulis cDNA } \\
\text { clone: bphylf053j04, full in- } \\
\text { sert sequence. }\end{array}$ & $\begin{array}{l}\text { Biological process: cellular } \\
\text { homeostasis }\end{array}$ \\
\hline Cluster-26447.109452 & G6PD_SOLTU & 0.015 & 9.75 & $\begin{array}{l}\text { Predicted: Setaria italica } \\
\text { glucose-6-phosphate } \\
\text { 1-dehydrogenase, } \\
\text { cytoplasmic isoform-like } \\
\text { (LOC101783950), mRNA. }\end{array}$ & $\begin{array}{l}\text { Molecular function: oxi- } \\
\text { doreductase activity, acting } \\
\text { on CH-OH group of donor. } \\
\text { Biological process: single- } \\
\text { organism carbohydrate } \\
\text { metabolic process, heterocy- } \\
\text { cle metabolic process, carbo- } \\
\text { hydrate derivative metabolic } \\
\text { process, organophosphate } \\
\text { metabolic process, organic } \\
\text { cyclic compound metabolic } \\
\text { process, single-organism } \\
\text { carbohydrate metabolic pro- } \\
\text { cess. }\end{array}$ \\
\hline
\end{tabular}


Table 2 (continued)

\begin{tabular}{|c|c|c|c|c|c|}
\hline Contig sequence ID & $\begin{array}{l}\text { UniProt } \\
\text { annotation }\end{array}$ & $\begin{array}{l}\text { FDR } \\
\text { (q-value) }\end{array}$ & $\begin{array}{l}\log _{2} \text {-fold } \\
\text { expression } \\
\text { change }\end{array}$ & Gene product and organism & Go terms \\
\hline Cluster-26447.60729 & G6PD4_ARATH & 0.045 & 9.36 & $\begin{array}{l}\text { Predicted: Setaria italica } \\
\text { glucose-6-phosphate 1- } \\
\text { dehydrogenase 4, chloro- } \\
\text { plastic (LOC101767719), } \\
\text { mRNA. }\end{array}$ & $\begin{array}{l}\text { Molecular function: nu- } \\
\text { cleotide binding. Biologi- } \\
\text { cal process: small molecule } \\
\text { metabolic process, cellu- } \\
\text { lar modified amino acid } \\
\text { metabolic process, phospho- } \\
\text { rus metabolic process, cel- } \\
\text { lular modified amino acid } \\
\text { metabolic process, small } \\
\text { molecule metabolic process, } \\
\text { nucleobase-containing com- } \\
\text { pound metabolic process. }\end{array}$ \\
\hline Cluster-26447.153858 & 6PGD1_ORYSJ & 0.025 & 8.78 & $\begin{array}{l}\text { Predicted: Setaria italica 6- } \\
\text { phosphogluconate dehydro- } \\
\text { genase, decarboxylating } 1 \\
\text { (LOC101779232), mRNA. }\end{array}$ & $\begin{array}{l}\text { Biological process: cellu- } \\
\text { lar aldehyde metabolic pro- } \\
\text { cess, nucleobase-containing } \\
\text { small molecule metabolic } \\
\text { process, cellular aldehyde } \\
\text { metabolic process, hete- } \\
\text { rocycle metabolic process, } \\
\text { organic cyclic compound } \\
\text { metabolic process, cellular } \\
\text { aldehyde metabolic process. }\end{array}$ \\
\hline Cluster-26447.153852 & 6PGD1_ORYSJ & 0.003 & -9.35 & $\begin{array}{l}\text { Predicted: Setaria italica 6- } \\
\text { phosphogluconate dehydro- } \\
\text { genase, decarboxylating 1- } \\
\text { like (LOC101785640), tran- } \\
\text { script variant X3, mRNA. }\end{array}$ & $\begin{array}{l}\text { Molecular function: coen- } \\
\text { zyme binding, nucleoside } \\
\text { phosphate binding; nu- } \\
\text { cleotide binding. Biologi- } \\
\text { cal process: single-organism } \\
\text { catabolic process, cellular } \\
\text { lipid metabolic process, or- } \\
\text { ganic acid metabolic pro- } \\
\text { cess, cellular biosynthetic } \\
\text { process, cellular amino acid } \\
\text { metabolic process. }\end{array}$ \\
\hline Cluster-26447.160591 & GSTF1_ORYSJ & 0.013 & 5.45 & - & - \\
\hline
\end{tabular}


Table 2 (continued)

\begin{tabular}{|c|c|c|c|c|c|}
\hline Contig sequence ID & $\begin{array}{l}\text { UniProt } \\
\text { annotation }\end{array}$ & $\begin{array}{l}\text { FDR } \\
(\boldsymbol{q} \text {-value })\end{array}$ & $\begin{array}{l}\log _{2} \text {-fold } \\
\text { expression } \\
\text { change }\end{array}$ & Gene product and organism & Go terms \\
\hline Cluster-26447.177110 & GSTF4_MAIZE & 0.012 & 5.07 & $\begin{array}{l}\text { Phyllostachys edulis cDNA } \\
\text { clone: bphylf052m02, full in- } \\
\text { sert sequence }\end{array}$ & - \\
\hline Cluster-26447.206365 & GSTU6_ORYSJ & 0.019 & 9.68 & $\begin{array}{l}\text { Predicted: Setaria italica } \\
\text { probable glutathione } \\
\text { S-transferase GSTU6 } \\
\text { (LOC101764179), mRNA. }\end{array}$ & - \\
\hline Cluster-26447.141508 & GSTU6_ORYSJ & 0.043 & 7.12 & $\begin{array}{l}\text { Sorghum bicolor hypothetical } \\
\text { protein, mRNA }\end{array}$ & - \\
\hline Cluster-26447.177111 & GSTF4_MAIZE & 0.012 & 10.31 & $\begin{array}{l}\text { Predicted: Setaria italica glu- } \\
\text { tathione S-transferase 4-like } \\
\text { (LOC101783467), mRNA. }\end{array}$ & - \\
\hline Cluster-26447.116962 & APX2_ORYSJ & 0.049 & 3.71 & $\begin{array}{l}\text { Predicted: Setaria italica L- } \\
\text { ascorbate peroxidase 2, cy- } \\
\text { tosolic (LOC101754668), } \\
\text { mRNA. }\end{array}$ & $\begin{array}{l}\text { Molecular function: } \\
\text { tetrapyrrole binding. }\end{array}$ \\
\hline
\end{tabular}




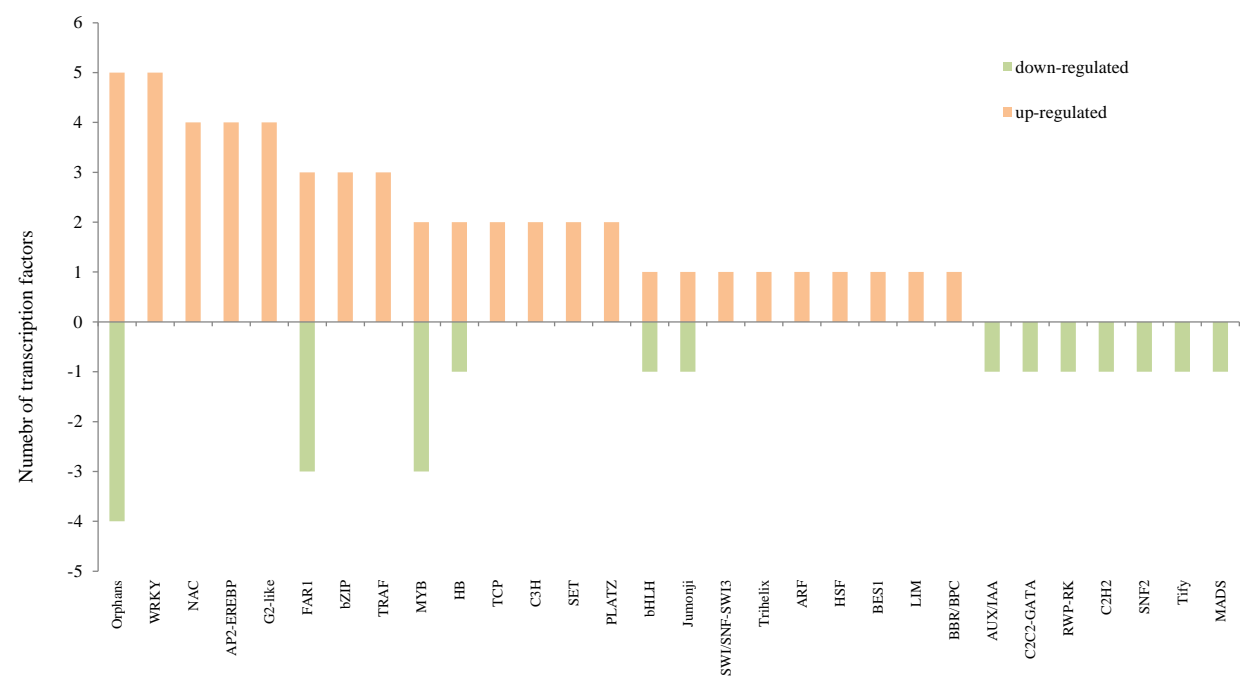

Figure 6 The top 10 transcription factors identified in the transcriptome analysis for "T300 vs T0". T0 is the tidal reeds with $0 \mathrm{mmol} / \mathrm{L} \mathrm{NaCl}$ treatment, and T300 is the tidal reed with $300 \mathrm{mmol} / \mathrm{L} \mathrm{NaCl}$ treatment.

Full-size DOI: 10.7717/peerj.10024/fig-6

ion-induced damage (Peng et al., 2014). Holmes et al. (2016) sampled their plant materials after an 8-week salt treatment, while we sampled the materials within $12 \mathrm{~h}$ of salt stress, during the $\mathrm{NaCl}$ and $\mathrm{ROS}$ accumulation period.

Furthermore, Holmes et al. (2016) reasoned that the higher relative expression levels of genes associated with photosynthesis and lignan biosynthesis under salt stress were indicative of a greater salt tolerance ability. In our study, a large number of DEGs (154) encoding oxidoreductase activity contributed to salt tolerance of the salt-tolerant reed under salt stress (Fig. 4). Reactive oxygen species were generated by salt stress, and a large number of gene families were involved in detoxifying ROS. Our results were consistent with previous studies of other plants: 150 DEGs were found be involved in regulating the level of ROS in Arabidopsis (Mittler et al., 2004) and $\mathrm{NaCl}$ treatment induced transcription of 75 ROS network genes in the roots of Arabidopsis (Jiang \& Deyholos, 2006). Moreover, our study is also consistent with comparative proteomics studies on non-model plants (e.g., Casuarina glauca and Zea mays L.), which revealed the importance of enhanced antioxidant status to resist salt stress (Chen et al., 2019; Graca et al., 2019).

Plant genomes encode many TFs governing transcriptional regulation, some of which allow for a switch from normal growth and development to salt stress-specific responses. TFs generally contain four functional regions: the DNA binding domain, the transcription regulatory domain, the oligomerization site and the nuclear localization signal. When plants are subjected to stress, TFs bind to cis-acting elements, activate transcriptional expression of genes, which allows them to regulate and mitigate the damage caused by stress to plants. We found that WRKY, Orphans, NAC, AP2-EREBP, and G2-like were key TF gene families regulating the response to salt stress for the salt-tolerant reed. Most of these genes were annotated as DNA-binding domains. Additionally, we found up-regulation of DAR1 in 
Table 3 Number of differentially expressed transcription factors identified in the transcriptome analysis. T0 means the tidal reed with $0 \mathrm{mmol} / \mathrm{L} \mathrm{NaCl}$ treatment. T300 is the tidal reed with $300 \mathrm{mmol} / \mathrm{L} \mathrm{NaCl}$ treatment. F0 indicates the freshwater reed with $0 \mathrm{mmol} / \mathrm{L} \mathrm{NaCl}$ treatment. $\mathrm{F} 300$ is the freshwater reed with $300 \mathrm{mmol} / \mathrm{L} \mathrm{NaCl}$ treatment.

\begin{tabular}{|c|c|c|c|c|}
\hline \multirow{2}{*}{ TF Family } & \multicolumn{2}{|c|}{ “T300 vs T0" } & \multicolumn{2}{|c|}{ “F300 vs F0" } \\
\hline & up-regulated & down-regulated & up-regulated & down-regulated \\
\hline WRKY & 5 & 0 & 0 & 0 \\
\hline Orphans & 5 & 4 & 0 & 1 \\
\hline NAC & 4 & 0 & 4 & 0 \\
\hline AP2-EREBP & 4 & 0 & 2 & 1 \\
\hline G2-like & 4 & 0 & 1 & 0 \\
\hline FAR1 & 3 & 3 & 1 & 0 \\
\hline bZIP & 3 & 0 & 0 & 0 \\
\hline TRAF & 3 & 0 & 0 & 0 \\
\hline TCP & 2 & 0 & 2 & 0 \\
\hline MYB & 2 & 3 & 1 & 0 \\
\hline $\mathrm{C} 3 \mathrm{H}$ & 2 & 0 & 1 & 0 \\
\hline $\mathrm{HB}$ & 2 & 1 & 1 & 2 \\
\hline SET & 2 & 0 & 0 & 1 \\
\hline PLATZ & 2 & 0 & 0 & 0 \\
\hline bHLH & 1 & 1 & 0 & 1 \\
\hline $\mathrm{ARF}$ & 1 & 0 & 0 & 0 \\
\hline HSF & 1 & 0 & 0 & 0 \\
\hline BES1 & 1 & 0 & 0 & 0 \\
\hline Jumonji & 1 & 1 & 0 & 0 \\
\hline SWI/SNF-SWI3 & 1 & 0 & 0 & 1 \\
\hline Trihelix & 1 & 0 & 0 & 1 \\
\hline LIM & 1 & 0 & 0 & 0 \\
\hline BBR/BPC & 1 & 0 & 0 & 0 \\
\hline AUX/IAA & 0 & 1 & 1 & 0 \\
\hline C2C2-GATA & 0 & 1 & 1 & 0 \\
\hline GeBP & 0 & 0 & 1 & 1 \\
\hline FHA & 0 & 0 & 1 & 0 \\
\hline EIL & 0 & 0 & 1 & 0 \\
\hline mTERF & 0 & 0 & 1 & 0 \\
\hline E2F-DP & 0 & 0 & 1 & 0 \\
\hline RWP-RK & 0 & 1 & 1 & 0 \\
\hline $\mathrm{C} 2 \mathrm{H} 2$ & 0 & 1 & 0 & 1 \\
\hline GRAS & 0 & 0 & 0 & 1 \\
\hline SNF2 & 0 & 1 & 0 & 1 \\
\hline Tify & 0 & 1 & 0 & 0 \\
\hline MADS & 0 & 1 & 0 & 0 \\
\hline
\end{tabular}




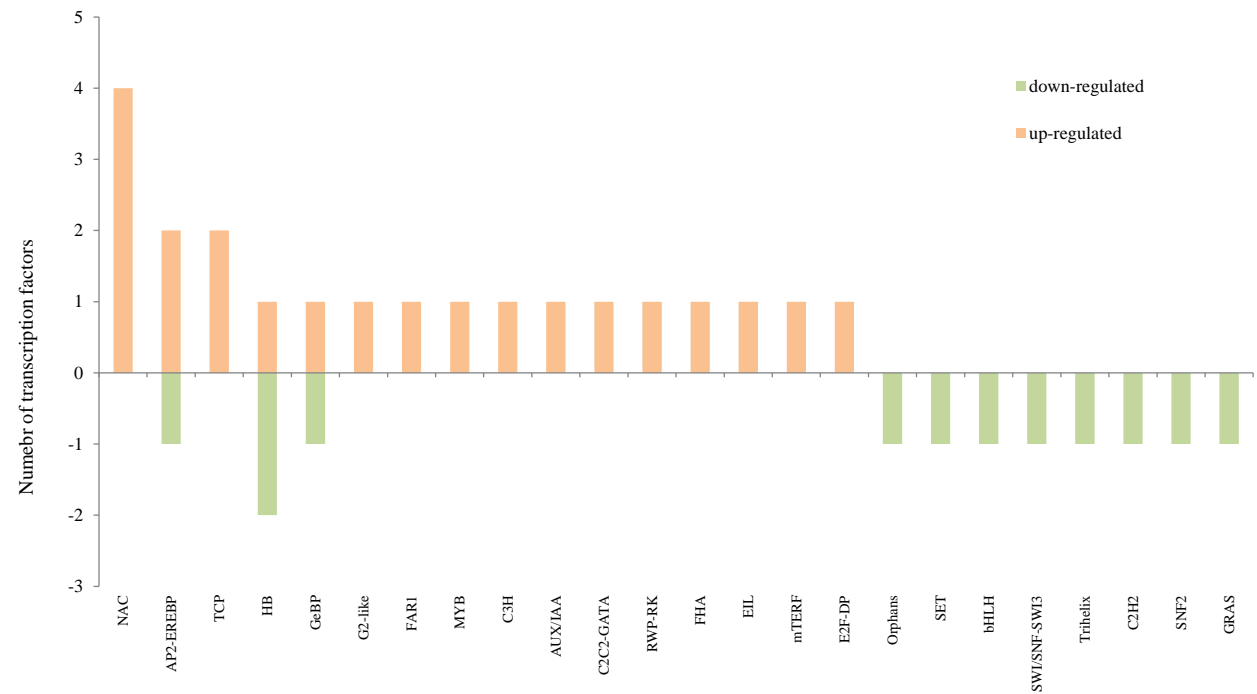

Figure 7 The top 10 transcription factors identified in the transcriptome analysis for "F300 vs F0". F0 indicates the freshwater reed with $0 \mathrm{mmol} / \mathrm{L} \mathrm{NaCl}$ treatment, and $\mathrm{F} 300$ is the freshwater reed with 300 $\mathrm{mmol} / \mathrm{L} \mathrm{NaCl}$ treatment.

Full-size DOI: 10.7717/peerj.10024/fig-7

the Orphans family, which is involved in oxidation-reduction process, and SALR in the Orphans family, which is related to oxidoreductase activity. The Orphans family genes may help in removing the ROS, thereby mitigating the potential damage caused by salt stress.

\section{Differential gene expression related to oxidoreductase activities}

In this study, we found many DEGs that encoded oxidoreductase activity in the common reed under salt stress. These results from transcriptome sequencing directly related to the eco-physiological responses we measured in previous studies (Chen et al., 2020). We previously found that for both F300 and T300, the levels of some oxidoreductase activities increased under salt stress, including hydrogen peroxide, catalase, superoxide dismutase, peroxidase, and malondialdehyde. In particular, GR of T300 increased compared to T0 (6.90 $\pm 1.73 \mathrm{U} /$ mgprot vs $3.54 \pm 0.54 \mathrm{U} /$ mgprot, $P<0.05)$, but there was no such trend for "F300 vs F0" (Chen et al., 2020). Higher levels of GR activity in T300 compared to T0 / F300 / F0 were verified in this study by the elevated transcript expression level of up-regulated genes involved in the GR in T300.

We identified the genes encoding antioxidant enzymes in the glutathione metabolism pathway, such as GR, G6PDH, GST and 6-PGD, which participated in the plant ascorbic acid glutathione cycle and removed redundant ROS in the tidal reed. In plant cells, redox homeostasis can be balanced by the oxidation states of glutathione. The reduced glutathione (GSH) metabolism includes GSH biosynthesis and accumulation, the oxidization of GSH to glutathione disulfide (GSSG), and the deoxidization of GSSG back to GSH by the action of GR. Therefore, GR plays an important role in maintaining the high GSH-GSSG ratio in plant cells (Noctor et al., 1998). Increasing GR activity acts a pivotal part in the tolerance of a range of environmental stressors (Kim et al., 2005; Lin et al., 2018; Sairam et al., 2005). For 
example, the over-expression of genes involved in GR (CrGR1 and CrGR2) can promote higher light tolerance in plants (Lin et al., 2018). More relevant to our study system, Li et al. (2018) found GPX- and GR-related peroxisomes were crucial in the tolerance of salt stress through ROS-scavenging. Reed seedlings of $P$. communis that were challenged with $\mathrm{NaCl}$ showed higher levels of GR activity and expression of the PhaGR gene. The increase in GR possibly increased the salt tolerance of reed plants through GSH production (Zhang et al., 2015). GR, G6PDH, GST and 6-PGD also played a protective role against ROS in the control of output of GSH from its oxidative form (GSSG) by utilizing NADPH (Wang et al., 2008). Our result was consistent with the study of common reed from Chen et al. (2003), which reported that higher rates of GSH biosynthesis and metabolism, as well as higher ratios of $\mathrm{NADPH} / \mathrm{NADP}{ }^{+}$and $\mathrm{NADH} / \mathrm{NAD}^{+}$, were found in the common reed responding to drought and salinity. Thus, genes involved in GSH metabolism were shown to be crucial to tolerating salt stress in the common reed.

Overexpression of TFs or genes involved in oxidoreductase activity in the resistance to salt stress can be realized in agriculture and management through genetic engineering. For example, in previous studies plasma membrane $\mathrm{Na}+/ \mathrm{H}^{+}$antiporter genes (PhaNHA1s) and HAK-type $\mathrm{K}^{+}$transporters (PhaHAK1 and PhaHAK5) in the salt-tolerant and saltsensitive common reed were cloned into yeast strains. In the presence of salt stress, yeast expressing genes from the salt-tolerant reed plants grew better than yeast expressing genes from salt-sensitive reed plants (Takahashi, Liu \& Takano, 2009; Takahashi et al., 2007). Recently, a GR gene named spGR was also cloned from Stipa purpurea into Arabidopsis thaliana, which subsequently allowed the genetically engineered plant to show greater tolerance to salt stress than the control plant (Wang et al., 2018). Therefore, genes encoding GR from the common reed in our study can be the potential target genes in improving the salt tolerance of plants through genetic manipulation.

In summary, by comparing gene expression levels between the tidal reed (a salt-tolerant common reed) and the freshwater reed (a salt-sensitive common reed) from the coastal wetlands of the Yellow River Delta under salt stress to reeds under a control, we were able to identify the molecular mechanisms of salt tolerance in the common reed. Genes encoding oxidoreductase activity were crucial for salt tolerance of the tidal common reed. In particular, GR produced by the glutathione metabolism pathway was crucial in eliminating ROS, which led to resistance to salt stress in the tidal reed. In future agricultural and ecosystem management planning, the genes involved in these processes could be used in transgenic plants to improve the salt tolerance of target plants.

Abbreviations
$\begin{array}{ll}\text { 6PGD } & \text { 6-phosphogluconate dehydrogenase } \\ \text { AP2/EREBP } & \text { Apetala2/ethylene response element binding protein } \\ \text { bHLH } & \text { basic Helix-Loop-Helix } \\ \text { bZIP } & \text { basic-domain leucine-zipper } \\ \text { DEGs } & \text { Differential expressed genes } \\ \text { DREB } & \text { Dehydration responsive element binding protein } \\ \text { ERF } & \text { Ethylene-responsive-element-binding factors }\end{array}$


G6PDH glucose-6-phosphate 1-dehydrogenase

GO Gene Ontology

GR Glutathione reductase

GSH Reduced glutathione

GSSG Oxidative glutathione

GST Glutathione S-transferase

HSF Heat shock factors

KEGG Kyoto encyclopedia of genes and genomes

LAP L-ascorbate peroxidase

MYB Myeloblastosis

NAC N-acetyl-L-cysteine

ROS Reactive oxygen species

TFs Transcription factors

\section{ACKNOWLEDGEMENTS}

We would like to thank Stephen Gaughran at Yale University for his assistance with English language and grammatical editing.

\section{ADDITIONAL INFORMATION AND DECLARATIONS}

\section{Funding}

This research has been funded by the National Natural Science Foundation of China (31670533), the Youth Innovation Promotion Association CAS (2018247), the Science and Technology Service Network Initiative (KFJ-STS-ZDTP-023) and the key Deployment Project of Chinese Academy of Sciences (KFZD-SW-112). The funders had no role in study design, data collection and analysis, decision to publish, or preparation of the manuscript.

\section{Grant Disclosures}

The following grant information was disclosed by the authors:

National Natural Science Foundation of China: 31670533.

Youth Innovation Promotion Association CAS: 2018247.

Science and Technology Service Network Initiative: KFJ-STS-ZDTP-023.

Key Deployment Project of Chinese Academy of Sciences: KFZD-SW-112.

\section{Competing Interests}

The authors declare there are no competing interests.

\section{Author Contributions}

- Liwen Zhang conceived and designed the experiments, analyzed the data, prepared figures and/or tables, authored or reviewed drafts of the paper, and approved the final draft.

- Lin Chen performed the experiments, analyzed the data, prepared figures and/or tables, authored or reviewed drafts of the paper, and approved the final draft. 
- Feng Lu, Ziting Liu and Guangxuan Han conceived and designed the experiments, authored or reviewed drafts of the paper, and approved the final draft.

- Siqun Lan performed the experiments, authored or reviewed drafts of the paper, and approved the final draft.

\section{Data Availability}

The following information was supplied regarding data availability:

All primary sequence read data are available in Figshare: Zhang, Liwen; Chen, Lin; Lan, Siqun; Liu, Ziting; Han, Guangxuan (2019): Freshwater common reeds in the Yellow River Delta responding to salt stress_CK. figshare. Dataset. https://doi.org/10.6084/m9.figshare. 10252847.v1

Zhang, Liwen; Chen, Lin; Lan, Siqun; Liu, Ziting; Han, Guangxuan (2019): Freshwater common reeds in the Yellow River Delta responding to salt stress_Salt stress. figshare. Dataset. https://doi.org/10.6084/m9.figshare.10257695.v1

Zhang, Liwen; Chen, Lin; Lan, Siqun; Liu, Ziting; Han, Guangxuan (2019): Tidal common reeds in the Yellow River Delta responding to salt stress_CK. figshare. Dataset. https://doi.org/10.6084/m9.figshare.10258724.v1

Zhang, Liwen; Chen, Lin; Lan, Siqun; Liu, Ziting; Han, Guangxuan (2019): Tidal common reeds in the Yellow River Delta responding to salt stress_Salt stress treatment. figshare. Dataset. https://doi.org/10.6084/m9.figshare.10259588.v1

They are also available at NCBI database under BioProject ID: PRJNA552916: SAMN12221419, SAMN12221420, SAMN12221421, SAMN12221422, SAMN12221423, SAMN12221424, SAMN12221425, SAMN12221426, SAMN12221427, SAMN12221428, SAMN12221429, SAMN12221430.

The assembled transcriptome sequences area are available in Figshare: Zhang, Liwen; Chen, Lin; Lu, Feng; Liu, Ziting; Lan, Siqun; Han, Guangxuan (2020): The assembled transcriptome of the tidal reeds and freshwater reeds in the Yellow River Delta responding to salt stress. figshare. Dataset. https://doi.org/10.6084/m9.figshare.12629885.v4.

The GO annotations of genes are available in the Supplementary Files.

\section{Supplemental Information}

Supplemental information for this article can be found online at http://dx.doi.org/10.7717/ peerj.10024\#supplemental-information.

\section{REFERENCES}

Achenbach L, Eller F, Nguyen LX, Brix H. 2013. Differences in salinity tolerance of genetically distinct Phragmites australis clones. Aob Plants 5:plt019 DOI 10.1093/aobpla/plt019.

Chen FQ, Fang P, Peng YL, Zeng WJ, Zhao XQ, Ding YF, Zhuang ZL, Gao QH, Ren B. 2019. Comparative proteomics of salt-tolerant and salt-sensitive maize inbred lines to reveal the molecular mechanism of salt tolerance. International Journal of Molecular Sciences 20: Article 4725 DOI 10.3390/Ijms20194725. 
Chen KM, Gong HJ, Chen GC, Wang SM, Zhang CL. 2003. Up-regulation of glutathione metabolism and changes in redox status involved in adaptation of reed (Phragmites communis) ecotypes to drought-prone and saline habitats. Journal of Plant Physiology 160:293-301 DOI 10.1078/0176-1617-00927.

Chen L, Zhang LW, Liu ZT, Lu F, Feng GH, Yan K, Han GX. 2020. Physiological and ecological responses of hetan and chaotan Phragmites australis to salt stress. Acta Ecologica Sinca 40(6):2090-2098 DOI 10.5846/stxb201812252799.

Clevering OA, Lissner J. 1999. Taxonomy, chromosome numbers, clonal diversity and population dynamics of Phragmites australis. Aquatic Botany 64:185-208 DOI 10.1016/S0304-3770(99)00059-5.

Cong PF, Chen KX, Qu LM, Han JB. 2019. Dynamic changes in the wetland landscape pattern of the Yellow River Delta from 1976 to 2016 based on satellite data. Chinese Geographical Science 29:372-381 DOI 10.1007/s11769-019-1039-x.

Do Amaral MN, Arge LWP, Benitez LC, Danielowski R, Silveira SFD, Farias DD, De Oliveira AC, Da Maia LC, Braga EJB. 2016. Comparative transcriptomics of rice plants under cold, iron, and salt stresses. Functional \& Integrative Genomics 16:567-579 DOI 10.1007/s10142-016-0507-y.

Du XL, Wang G, Ji J, Shi LP, Guan CF, Jin C. 2017. Comparative transcriptome analysis of transcription factors in different maize varieties under salt stress conditions. Plant Growth Regulation 81:183-195 DOI 10.1007/s10725-016-0192-9.

Eller F, Skalova H, Caplan JS, Bhattarai GP, Burger MK, Cronin JT, Guo WY, Guo X, Hazelton ELG, Kettenring KM, Lambertini C, McCormick MK, Meyerson LA, Mozdzer TJ, Pysek P, Sorrell BK, Whigham DF, Brix H. 2017. Cosmopolitan species as models for ecophysiological responses to global change: the common reed Phragmites australis. Frontiers in Plant Science 8:1-24.

Gao LX, Tang SQ, Zhuge LQ, Nie M, Zhu Z, Li B, Yang J. 2012. Spatial genetic structure in natural populations of Phragmites australis in a mosaic of saline habitats in the Yellow River Delta, China. PLOS ONE 7(8):e43334.

Gong QQ, Li PH, Ma SS, Rupassara SI, Bohnert HJ. 2005. Salinity stress adaptation competence in the extremophile Thellungiella halophila in comparison with its relative Arabidopsis thaliana. Plant Journal 44:826-839

DOI 10.1111/j.1365-313X.2005.02587.x.

Gorai M, Ennajeh M, Khemira H, Neffati M. 2011. Influence of NaCl-salinity on growth, photosynthesis, water relations and solute accumulation in Phragmites australis. Acta Physiologiae Plantarum 33:963-971 DOI 10.1007/s11738-010-0628-1.

Goyal E, Amit SK, Singh RS, Mahato AK, Chand S, Kanika K. 2016. Transcriptome profiling of the salt-stress response in Triticum aestivum cv. Kharchia Local. Scientific Reports 6:27752 DOI 10.1038/Srep27752.

Grabherr MG, Haas BJ, Yassour M, Levin JZ, Thompson DA, Amit I, Adiconis X, Fan L, Raychowdhury R, Zeng QD, Chen ZH, Mauceli E, Hacohen N, Gnirke A, Rhind N, Di Palma F, Birren BW, Nusbaum C, Lindblad-Toh K, Friedman N, Regev A. 2011. 
Full-length transcriptome assembly from RNA-Seq data without a reference genome. Nature Biotechnology 29:644-U130 DOI 10.1038/nbt.1883.

Graca I, Mendes VM, Marques I, Duro N, Da Costa M, Ramalho JC, Pawlowski K, Manadas B, Pinto Ricardo CP, Ribeiro-Barros AI. 2019. Comparative proteomic analysis of nodulated and non-nodulated Casuarina glauca Sieb. ex Spreng. grown under salinity conditions using sequential window acquisition of all theoretical mass spectra (SWATH-MS). International Journal of Molecular Sciences 21(1):78 DOI 10.3390/ijms21010078.

Guan L, Haider MS, Khan N, Nasim M, Jiu ST, Fiaz M, Zhu XD, Zhang KK, Fang JG. 2018. Transcriptome sequence analysis elaborates a complex defensive mechanism of grapevine (Vitis vinifera L.) in response to salt stress. International Journal of Molecular Sciences 19(12):4019 DOI 10.3390/Ijms19124019.

Guan B, Yu JB, Cao D, Li YZ, Han GX, Mao PL. 2013. The ecological restoration of heavily degraded saline wetland in the Yellow River Delta. Clean-Soil Air Water 41:690-696 DOI 10.1002/clen.201200569.

Guan B, Yu JB, Hou AX, Han GX, Wang GM, Qu FZ, Xia JB, Wang XH. 2017. The ecological adaptability of Phragmites australis to interactive effects of water level and salt stress in the Yellow River Delta. Aquatic Ecology 51:107-116 DOI 10.1007/s10452-016-9602-3.

Guo PG, Baum M, Grando S, Ceccarelli S, Bai GH, Li RH, Von Korff M, Varshney RK, Graner A, Valkoun J. 2009. Differentially expressed genes between droughttolerant and drought-sensitive barley genotypes in response to drought stress during the reproductive stage. Journal of Experimental Botany 60:3531-3544 DOI 10.1093/jxb/erp194.

Guo WH, Wang RQ, Zhou SL, Zhang SP, Zhang ZG. 2003. Genetic diversity and clonal structure of Phragmites australis in the Yellow River delta of China. Biochemical Systematics and Ecology 31:1093-1109 DOI 10.1016/S0305-1978(03)00032-2.

Hickman R, Hill C, Penfold CA, Breeze E, Bowden L, Moore JD, Zhang PJ, Jackson A, Cooke E, Bewicke-Copley F, Mead A, Beynon J, Wild DL, Denby KJ, Ott S, Buchanan-Wollaston V. 2013. A local regulatory network around three NAC transcription factors in stress responses and senescence in Arabidopsis leaves. Plant Journal 75:26-39 DOI 10.1111/tpj.12194.

Holmes GD, Hall NE, Gendall AR, Boon PI, James EA. 2016. Using transcriptomics to identify differential gene expression in response to salinity among Australian Phragmites australis clones. Frontiers in Plant Science 7:432 DOI 10.3389/Fpls.2016.00432.

Jiang YQ, Deyholos MK. 2006. Comprehensive transcriptional profiling of $\mathrm{NaCl}$-stressed Arabidopsis roots reveals novel classes of responsive genes. BMC Plant Biology 6:1-20 DOI 10.1186/1471-2229-6-25.

Kanehisa M, Araki M, Goto S, Hattori M, Hirakawa M, Itoh M, Katayama T, Kawashima S, Okuda S, Tokimatsu T, Yamanishi Y. 2008. KEGG for linking genomes to life and the environment. Nucleic Acids Research 36:D480-D484 DOI 10.1093/nar/gkm882. 
Kanehisa M, Sato Y. 2019. KEGG Mapper for inferring cellular functions from protein sequences. Protein Science DOI 10.1002/pro.3711.

Kim SY, Lim JH, Park MR, Kim YJ, Park TI, Se YW, Choi KG, Yun SJ. 2005. Enhanced antioxidant enzymes are associated with reduced hydrogen peroxide in barley roots under saline stress. Journal of Biochemistry and Molecular Biology 38:218-224.

Li MN, Zhang K, Sun Y, Cui HT, Cao SH, Yan L, Xu MX. 2018. Growth, physiology, and transcriptional analysis of two contrasting Carex rigescens genotypes under salt stress reveals salt-tolerance mechanisms. Journal of Plant Physiology 229:77-88 DOI 10.1016/j.jplph.2018.07.005.

Lin TH, Rao MY, Lu HW, Chiou CW, Lin ST, Chao HW, Zheng ZL, Cheng HC, Lee TM. 2018. A role for glutathione reductase and glutathione in the tolerance of Chlamydomonas reinhardtii to photo-oxidative stress. Physiologia Plantarum 162:35-48 DOI 10.1111/ppl.12622.

Love MI, Huber W, Anders S. 2014. Moderated estimation of fold change and dispersion for RNA-seq data with DESeq2. Genome Biology 15:Article 550 DOI 10.1186/S13059-014-0550-8.

Mansuri RM, Shobbar ZS, Jelodar NB, Ghaffari MR, Nematzadeh GA, Asari S. 2019. Dissecting molecular mechanisms underlying salt tolerance in rice: a comparative transcriptional profiling of the contrasting genotypes. Rice 12:13 DOI 10.1186/s12284-019-0273-2.

Mao XZ, Cai T, Olyarchuk JG, Wei LP. 2005. Automated genome annotation and pathway identification using the KEGG Orthology (KO) as a controlled vocabulary. Bioinformatics 21:3787-3793 DOI 10.1093/bioinformatics/bti430.

Mauchamp A, Mesleard F. 2001. Salt tolerance in Phragmites australis populations from coastal Mediterranean marshes. Aquatic Botany 70:39-52 DOI 10.1016/S0304-3770(00)00140-6.

Mittler R, Vanderauwera S, Gollery M, Van Breusegem F. 2004. Reactive oxygen gene network of plants. Trends in Plant Science 9:490-498

DOI 10.1016/j.tplants.2004.08.009.

Noctor G, Arisi ACM, Jouanin L, Kunert KJ, Rennenberg H, Foyer CH. 1998. Glutathione: biosynthesis, metabolism and relationship to stress tolerance explored in transformed plants. Journal of Experimental Botany 49:623-647 DOI 10.1093/jexbot/49.321.623.

Peng Z, He SP, Gong WF, Sun JL, Pan ZE, Xu FF, Lu YL, Du XM. 2014. Comprehensive analysis of differentially expressed genes and transcriptional regulation induced by salt stress in two contrasting cotton genotypes. BMC Genomics 15:760 DOI 10.1186/1471-2164-15-760.

Roy SJ, Negrao S, Tester M. 2014. Salt resistant crop plants. Current Opinion in Biotechnology 26:115-124 DOI 10.1016/j.copbio.2013.12.004.

Sairam RK, Srivastava GC, Agarwal S, Meena RC. 2005. Differences in antioxidant activity in response to salinity stress in tolerant and susceptible wheat genotypes. Biologia Plantarum 49:85-91 DOI 10.1007/s10535-005-5091-2. 
Singh KB, Foley RC, Onate-Sanchez L. 2002. Transcription factors in plant defense and stress responses. Current Opinion in Plant Biology 5:430-436 DOI 10.1016/S1369-5266(02)00289-3.

Storey JD, Tibshirani R. 2003. Statistical significance for genomewide studies. Proceedings of the National Academy of Sciences of the United States of America 100:9440-9445 DOI 10.1073/pnas.1530509100.

Taji T, Seki M, Satou M, Sakurai T, Kobayashi M, Ishiyama K, Narusaka Y, Narusaka M, Zhu JK, Shinozaki K. 2004. Comparative genomics in salt tolerance between Arabidopsis and Arabidopsis-related halophyte salt cress using Arabidopsis microarray. Plant Physiology 135:1697-1709 DOI 10.1104/pp.104.039909.

Takahashi R, Liu S, Takano T. 2009. Isolation and characterization of plasma membrane $\mathrm{Na}+/ \mathrm{H}^{+}$antiporter genes from salt-sensitive and salt-tolerant reed plants. Journal of Plant Physiology 166:301-309 DOI 10.1016/j.jplph.2008.04.002.

Takahashi R, Nishio T, Ichizen N, Takano T. 2007. Cloning and functional analysis of the $\mathrm{K}^{+}$transporter, PhaHAK2, from salt-sensitive and salt-tolerant reed plants. Biotechnology Letters 29:501-506 DOI 10.1007/s10529-006-9246-9.

Wang QL, Pu YA, Yang DN, Yin X, He ZR, Yang YQ, Yang YP. 2018. Molecular cloning and characterization of the glutathione reductase gene from Stipa purpurea. Biochemical and Biophysical Research Communications 495:1851-1857 DOI 10.1016/j.bbrc.2017.12.054.

Wang X, Ma Y, Huang C, Wan Q, Li N, Bi Y. 2008. Glucose-6-phosphate dehydrogenase plays a central role in modulating reduced glutathione levels in reed callus under salt stress. Planta 227:611-623 DOI 10.1007/s00425-007-0643-7.

Wu Q, Bai X, Zhao W, Xiang DB, Wan Y, Yan J, Zou L, Zhao G. 2017. De Novo assembly and analysis of tartary buckwheat (Fagopyrum tataricum Garetn.) transcriptome discloses key regulators involved in salt-stress response. Gene 8(10):225 DOI 10.3390/Genes8100255.

Yang ZF, Xie T, Liu Q. 2014. Physiological responses of Phragmites australis to the combined effects of water and salinity stress. Ecohydrology 7:420-426 DOI 10.1002/eco.1361.

Young MD, Wakefield MJ, Smyth GK, Oshlack A. 2010. Gene ontology analysis for RNA-seq: accounting for selection bias. Genome Biology 11:R14 DOI 10.1186/Gb-2010-11-2-R14.

Zhang X, Quan G, Wang J, Han HL, Chen SH, Guo SL, Yin HB. 2015. Functional validation of Phragmites communis glutathione reductase (PhaGR) as an essential enzyme in salt tolerance. Applied Biochemistry and Biotechnology 175:3418-3430 DOI 10.1007/s12010-015-1514-5.

Zhang LW, Wang BC, Qi LB. 2017. Phylogenetic relatedness, ecological strategy, and stress determine interspecific interactions within a salt marsh community. Aquatic Sciences 79:587-595 DOI 10.1007/s00027-017-0519-2. 
Zhang LW, Wang AD, Zhao YJ, Chen L, Song JB, Yang CZ, Han GX. 2018. Genetic variation of Phragmites australis and its relationship with salinity in the coastal wetland of Yellow River Delta. Chinese Journal of Ecology (Chinese version) 37:2362-2368.

Zheng Y, Jiao C, Sun HH, Rosli HG, Pombo MA, Zhang PF, Banf M, Dai XB, Martin GB, Giovannoni JJ, Zhao PX, Rhee SY, Fei ZJ. 2016. iTAK: a program for genome-wide prediction and classification of plant transcription factors, transcriptional regulators, and protein kinases. Molecular Plant 9:1667-1670 DOI 10.1016/j.molp.2016.09.014. 